\title{
Integrated supply chain inventory model with quality improvement involving controllable lead time and backorder price discount
}

\author{
Prashant Jindal $^{a^{*}}$ and Anjana Solanki ${ }^{b}$
}

${ }^{a}$ Research scholar, Department of Applied Mathematics, Gautam Buddha University, Greater Noida, Uttar Pradesh, India ${ }^{b}$ Professor, Department of Applied Mathematics, Gautam Buddha University, Greater Noida, Uttar Pradesh, India

CHRONICLE ABSTRACT

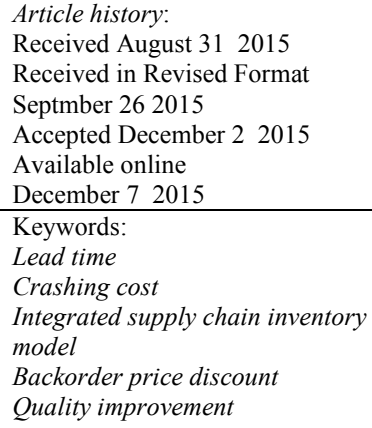

\begin{abstract}
For the past four decades the integrated vendor and buyer supply chain inventory model has been an interesting topic, but quality improvement of defective items in the integrated inventory model with backorder price discount involving controllable lead time has been rarely discussed. The aim of this paper is to minimize the total related cost in the continuous review model by considering the order quantity, reorder point, lead time, process quality, backorder price discount and number of shipment as decision variables. Moreover, we assume that an investment function is used to improve the process quality. The lead time demand follows a normal distribution. In addition, the buyer offers backorder price discount to motivate the customers for possible backorders. There are some defective items in the arrival lot, so its treatment is also taken in account in this paper. We develop an iterative procedure for finding the optimal values of decision variables and numerical example is presented to illustrate the solution procedure. Additionally, sensitivity analysis with respect to major parameters is also carried out.
\end{abstract}

\section{Introduction}

In the classical inventory models, it is often seen that the setup/ordering cost and lead time are constant and not subject to control. However, this may not be a realistic situation; for example, in many practical situations, lead time can be shortened at an added cost, and hence lead time is controllable. The first papers dealing with a variable lead time in an inventory model was provided by Liao and Shyu (1991). They assumed that lead time can be decomposed into several components, each having a different piecewise linear crashing cost function for lead time reduction, and that each component may be reduced to a given minimum duration. Under the assumption that the lot size is predetermined and that demand is normally distributed, they calculated an optimal value of lead time and explained that reducing lead time may result in lower expected total costs. Ben-Daya and Raouf (1994) resumed Liao and Shyu (1991) and proposed a model considering both lead time and order quantity as decision variables. They

* Corresponding author

E-mail: pras.jindal@gmail.com (P. Jindal)

(C) 2016 Growing Science Ltd. All rights reserved. doi: 10.5267/j.ijiec.2015.12.003 
developed two models, one that uses the lead time crashing cost-function proposed by Liao and Shyu and one that uses an exponential crashing cost function. Ouyang et al. (1996) provided another extension and included shortages in that model. They assumed that a certain fraction of the demand during the stockout period is backordered and that the remaining fraction in lost sales.

Pan and Yang (2002) were the first authors who studied lead time reduction in an integrated inventory model. They considered a system where a single vendor delivers a product to a single buyer and assumed that the vendor may reduce lead time according to the scheme proposed by Liao and Shyu (1991). Under the assumption that lead time crashing costs incurred by the vendor are fully transferred to the buyer if shortened lead time is requested, they calculated an optimal lead time length that minimizes total system costs. Ouyang et al. (2004) developed Pan and Yang (2002) and included shortage costs in the model formulation. Further, they assumed that only the first and second moments of the probability of lead time demand were known and finite and solved the model using the minimax distribution-free approach. The minimax distribution free approach was originally proposed by Scarf (1958). Thereafter, Gallego and Moon (1993) presented a new and very compact proof of the optimality of Scarf's (1958) ordering rule. Further extensions can be found in Yang and Pan (2004), who included quality considerations in the model formulation or in Hoque (2007), who studied the effect of lead time reduction and different batch sizes on the coordination of a single- vendor-single-buyer system,

A common impractical assumption of the above inventory models is that all items produced are assumed to be of good quality. However due to various factors such as damage in transit, imperfect production processes of the vendor, or other circumstances, an order lot arriving at the buyer often may contain some defective goods. The presence of these defective goods in arrival lots will affect the on hand inventory level, customer service level and the frequency of orders. In the real production environment, it can often be observed that there are defective items being produced due to imperfect production processes. The defective items must be rejected, repaired, reworked, or, if they have reached the customer, refunded. In all cases, substantial costs are incurred. Therefore, for the system with an imperfect production process, the manager may consider investing capital on quality improvement, to reduce the quality-related costs. In literature, Porteus (1986) and Rosenblatt and Lee (1986) were among the first who explicitly elaborated on a significant relationship between quality imperfection and lot size. Keller and Noori (1988) extended Porteus' (1986) work to the situation where the demand during lead time was probabilistic and shortages were allowed. Hwang et al. (1993) studied the multiproduct economic lot size models in which setup reduction and quality improvement can be achieved with a one-time initial investment. Hong and Hayya (1995) presented a model including a budget constraint and other types of continuous functions for quality enhancement and setup cost reduction. Ouyang and Chang (2000) investigated the impact of quality improvement on the modified lot size reorder point models involving variable lead time and partial backorders.

In order to compensate customers for the trouble of waiting, loss of production in the stockout period, the supplier may offer a price discount on the stockout item for more backordering. Thus, both the backorder discount and the lead-time should be managed in such a way that the supplier could reduce the present and the future profit losses and the customers get the item as soon as possible. Pan and Hsiao (2005) presented integrated supply chain inventory model with controllable lead time and backorder price discount to reduce lost sales. In this study, lead time crashing cost is represented as a function of reduced lead time. Hoque and Goyal (2006) developed a heuristic procedure for an integrated inventory system under controllable lead time for both shipment sizes either equal or unequal, between the vendor and buyer. Wu et al. (2007) formulated an integrated inventory model with sub-lot sampling inspection policy and controllable type of lead time. Lin (2008) analyzed the continuous review inventory model in which he considered the lead time and ordering cost reductions work interdependently with backorder price discount. Further, Lin (2009) proposed an integrated supply chain vendor-buyer model with backorder price discount and effective investment to reduce ordering cost. Annadurai and Uthayakumar (2010) formulated a continuous review inventory model including defective items with controllable setup cost 
by discussing both normal distribution model and distribution-free model. In this paper, they allowed order quantity, reorder point and lead time as decision variables in conjunction with setup cost. Jauhari et al. (2011) developed vendor-buyer model considering variable lead time. They gave the flexibility to both vendor and buyer to determine the production cycle and delivery cycle. Ma and Qiu (2012) developed a continuous review inventory model with a controllable lead time and setup cost reduction in the presence of a service level constraint. Chen (2013) developed a model to rework imperfect items and to offer an inspection strategy that prevents maintenance error. Jindal and Solanki (2014) discussed integrated inventory model with backorder price discount and controllable lead time. Sarkar and Moon (2014) derived an inventory model with setup cost reduction, quality improvement, and variable backorder rate. They used the logarithmic investment function for setup cost reduction and quality improvement by assuming a variable backorder rate. Recently, Sarkar et al. (2015) discussed about two models, first model with normally distributed lead time demand and the second model without any specific distribution with known mean and standard deviation. They minimized the total expected cost with order quantity, reorder point, backorder price discount, process quality, and lead time as decision variables. A logarithmic investment function was considered to improve the quality of products. More recently, Jindal and Solanki (2016) presented two single-vendor single-buyer integrated supply chain inventory models with inflation and time value of money. Shortage was allowed during the lead time and it was partially backlogged in that paper.

In the present volatile marketing environment, company's strategy must be accustomed as per situation. Lead time and lost sales are two major factors in growth of any company. To reimburse customers for the trouble of waiting, or lost sales meanwhile the shortages, the supplier often provide a backorder price discount on the stockout item based on the backorder condition. Lead time has a considerable impact on both the supplier's and the retailer's inventory decisions and the reduction of lead time may involve with all trading parties to improve the related operations in a supply chain. There are some defective items in the arrival lot, so its treatment is also considered in this paper.

The paper is organized as follows. In section 2, the notation and assumptions are presented. In Section 3 , we formulate the integrated vendor-buyer model involving imperfect-quality items and controllable lead time. Section 4 provides solution procedure, and then develops an algorithm to find the optimal solution. In section 5, a numerical example and discussion of the results along with sensitivity analysis are presented. In Section 6, we give conclusion and suggestions for the future research.

\section{Notations and assumptions}

To develop the proposed model, we adopt the following notations and assumptions.

\subsection{Notations}

$\mathrm{D}=$ Demand rate on the buyer (for non-defective items)

$\mathrm{P} \quad=$ Production rate on the vendor

$\mathrm{A}_{\mathrm{b}} \quad=$ Buyer's ordering cost per order

$\mathrm{h}_{\mathrm{b} 1}=$ Buyer's holding cost per non-defective item per unit time

$\mathrm{h}_{\mathrm{b} 2}=$ Buyer's treatment cost (including holding cost) per defective item per unit time

$\mathrm{A}_{\mathrm{v}} \quad=$ Vendor's setup cost per setup

$\mathrm{h}_{\mathrm{v} 1} \quad=$ Vendor's holding cost per item per unit time

$\mathrm{h}_{\mathrm{v} 2}=$ Vendor's unit treatment cost (including warranty cost) of defective items

$\mathrm{F} \quad=$ Transportation cost per delivery 
$\mathrm{s} \quad=$ Buyer's unit inspection cost

$\mathrm{d} \quad=$ Cost of replacing a defective item (including guaranty cost)

$\pi_{x}=$ Backorder price discount offered by the supplier per unit (decision variable)

$\pi_{o} \quad=$ Buyer's marginal profit per unit, i.e., cost of lost demand per unit

$\beta=$ Fraction of the demand during the stockout period that will be backordered, $\beta \in[0,1]$

$\beta_{o}=$ Upper bound of backorder ratio, $0<\beta_{o}<1$

$\theta \quad=$ Probability that the vendor's production process can go out of control

$\theta_{0}=$ Original probability that vendor's production process can go out of control, $0<\theta \leq \theta_{0}$

$\alpha \quad=$ Fractional per unit time opportunity cost of capital

$\lambda=$ Defective rate in an order let, $\lambda \in[0,1]$

$g(\lambda)=$ Probability density function (p.d.f.) of $\lambda$ with finite mean $M$ and variance $V$

$\mathrm{Q} \quad=$ Order quantity (for non-defective goods) of the buyer (decision variable)

$\mathrm{q}=$ Shipping quantity from vendor to buyer per shipment (decision variable)

$\mathrm{r} \quad=$ Reorder point of the buyer for non-defective goods (decision variable)

$L \quad=$ Length of lead time for the buyer (decision variable)

$\mathrm{m}=$ Number of shipments in one production cycle, a positive integer (decision variable)

$\mathrm{X}=$ Lead time demand with finite mean DL and standard deviation $\sigma \sqrt{L}>0$

$\mathrm{E}($. ) = Mathematical expectation

$\mathrm{x}^{+}=$Maximum value of $\mathrm{x}$ and 0 , i.e., $\mathrm{x}^{+}=\operatorname{Max}\{\mathrm{x}, 0\}$.

\subsection{Assumptions}

1. Inventory is continuously reviewed and replenishments are made whenever the inventory level (based on the number of non-defective items) falls to the reorder point $r$.

2. The reorder point $r=$ expected demand during lead time + safety stock (SS) and $S S=k \times$ (standard deviation of lead time demand), that is, $r=D L+k \sigma \sqrt{L}$ where $k$ is the safety factor.

3. The buyer orders a lot of size $Q$ and will receive the batch quantity in m equal sized shipments of size $q$.

4. The expected quantity of non-defective items is $(1-M) q$ in each shipment and the order quantity $\mathrm{Q}$, is the sum of non-defective units in n shipments, therefore $Q=m(1-M) q$.

5. Inspection is nondestructive and error-free. The process of inspection is done quickly, so that the length of inspection period is neglected here.

6. The vendor's production rate is finite. The expected production rate of non-defective items is greater than the buyer's demand rate, i.e., $P(1-M)>D$.

7. The lead time $\mathrm{L}$ consists of $\mathrm{n}$ mutually independent components. The $\mathrm{i}^{\text {th }}$ component has a minimum duration $\mathrm{a}_{\mathrm{i}}$, normal duration $\mathrm{b}_{\mathrm{i}}$, and crashing cost per unit time $\mathrm{c}_{\mathrm{i}}$. For convenience, we rearrange $c_{\mathrm{i}}$ such that $c_{1} \leq c_{2} \leq \leq c_{m}$. The components of lead time are crashed one at a time starting from the first component because it has the minimum unit crashing cost, and then the second component, and so on.

8. Let $L_{o}=\sum_{j=1}^{n} b_{j}$ and $\mathrm{L}_{\mathrm{i}}$ be the length of lead time with components $1,2, \ldots, \mathrm{i}$ crashed to their minimum duration, then $\mathrm{L}_{\mathrm{i}}$ can be expressed as $L_{i}=\sum_{j=1}^{n} b_{j}-\sum_{j=1}^{i}\left(b_{j}-a_{j}\right), \mathrm{i}=1,2, \ldots, \mathrm{n}$; and the lead time crashing cost $\mathrm{C}(\mathrm{L})$ per cycle for a given $L \in\left[L_{i}, L_{i-1}\right]$, is given by $C(L)=$ 
$c_{i}\left(L_{i-1}-L_{i}\right)+\sum_{j=1}^{i-1} c_{j}\left(b_{j}-a_{j}\right)$. In addition, the length of lead time is equal for all shipping cycles, and the lead time crashing cost occurs in each cycle.

9. To reduce imperfect production rate, the vendor's capital investment, $I(\theta)$, for improving process quality (reducing out of control probability from $\theta_{0}$ to $\theta$ ) is given by a logarithmic function, $I(\theta)=b \ln \left(\frac{\theta_{0}}{\theta}\right)$ for $0<\theta \leq \theta_{0}$ where $b=\frac{1}{\delta}$, and $\delta$ is the percentage decrease in $\theta$ per dollar increase in $I(\theta)$. This investment function was suggested by porteus (1986) and was used by many other researchers thereafter.

\section{Model formulation}

In this paper, we develop an integrated single vendor-buyer supply chain inventory model with defective items and controllable lead time. As soon as the production of first $q$ units is completed, the vendor will deliver them to the buyer. After that the deliveries will schedule on average every $q(1-M) / D$ units of time until the inventory level vanishes. All lots are quickly inspected by the buyer and all defective units will be separated and returned to the vendor at the time of next lot is arrived. Clearly $Q=$ $m q(1-M)$. Inventory follows continuous review pattern; we assume that the integrated production inventory model allows shortages with partial backordering with backorder price discount. Replenishments are made whenever the inventory level falls to the reorder point $\mathrm{r}$. The lead time demand $\mathrm{X}$ has a p.d.f. $\mathrm{f}(\mathrm{x})$ with finite mean $\mathrm{DL}$ and standard deviation $\sigma \sqrt{\mathrm{L}}>0$. The reorder point $r=D L+$ $k \sigma \sqrt{L}$, where $\mathrm{k}$ is the safety factor.

\subsection{Buyer's expected total cost per unit time}

The expected non-defective net inventory level just before the order arrives is $\mathrm{r}-\mathrm{DL}+$ $(1-\beta) E(X-r)^{+}$, and the expected non-defective inventory level immediately after the shipment is $(1-\lambda) q+r-D L+(1-\beta) E(X-r)^{+}$. Therefore the average non-defective inventory level per cycle is $(1-\lambda) \frac{q}{2}+r-D L+(1-\beta) E(X-r)^{+}$. Since $\mathrm{D}$ is the demand per unit time for non-defective items, and $(1-\lambda) q$ is the quantity of non-defective items in each shipment, the length of an inventory cycle time is $(1-\lambda) q / D$, the remaining item's (non-defective items) holding cost per cycle is $h_{b 1}\left[(1-\lambda) \frac{q}{2}+r-D L+(1-\beta) E(X-r)^{+}\right] \frac{(1-\lambda) q}{D}$ and the defective items treatment cost per cycle is $h_{b 2} \lambda q \frac{(1-\lambda) q}{D}$. Since the expected shortages at the end of each shipping cycle is $E(X-r)^{+}$. Therefore the expected number of backorders and loss in sales per shipping cycle are $\beta E(X-r)^{+}$and $(1-$ $\beta) E(X-r)^{+}$respectively, and hence, the stockout cost per cycle is $\left[\pi_{x} \beta+\pi_{o}(1-\beta)\right] E(X-r)^{+}$. Further, during the stockout period, the backorder ratio $\beta$ is variable and is proportional to the backorder price discount offered by the buyer per unit, $\pi_{x}$, therefore, $\beta=\frac{\beta_{o} \pi_{x}}{\pi_{o}}$. Thus, $\pi_{x}$, can be treated as a decision variable instead of $\beta$. The buyer's total cost per cycle is the sum of the ordering cost, transportation cost, screening cost, stockout cost, defective items treatment cost, non-defective items holding cost and leadtime crashing cost, and is expressed by

$$
\begin{aligned}
& T C_{b}\left(q, r, \pi_{x}, L, m\right)=A_{b}+F+s q+\left[\frac{\beta_{0} \pi_{x}^{2}}{\pi_{0}}+\pi_{0}\left(1-\frac{\beta_{0} \pi_{x}}{\pi_{0}}\right)\right] E(X-r)^{+}+h_{b 2} \lambda q \frac{(1-\lambda) q}{D}+h_{b 1} \\
& {\left[\frac{(1-\lambda) q}{2}+r-D L+\left(1-\frac{\beta_{0} \pi_{x}}{\pi_{0}}\right) E(X-r)^{+}\right] \frac{(1-\lambda) q}{D}+C(L)}
\end{aligned}
$$

Since the defective rate $\lambda$ is a random variable with p.d.f. $g(\lambda)$, the expected defective rate is $M=$ $\int_{0}^{1} \lambda \mathrm{g}(\lambda) \mathrm{d} \lambda$. Hence the expected non-defective goods in each cycle will be $q(1-M)$. Thus, the expected order per unit time is $D / q(1-M)$. Therefore, the expected total cost per unit time for the buyer is 


$$
\begin{aligned}
& E_{C_{b}\left(q, r, \pi_{x}, L, m\right)=E\left[T C_{b}\left(q, r, \pi_{x}, L, m\right)\right] \frac{D}{(1-M) q}} \\
& =\frac{D}{(1-M) q}\left[A_{b}+F+C(L)+G\left(\pi_{x}\right) E(X-r)^{+}\right]+\frac{s D}{(1-M)}+\frac{Y q}{2(1-M)}+h_{b 1}\left[r-D L+\left(1-\frac{\beta_{0} \pi_{x}}{\pi_{0}}\right)\right. \\
& \left.\quad E(X-r)^{+}\right]
\end{aligned}
$$

Where, $Y=2 h_{b 2} \int_{0}^{1} \lambda(1-\lambda) g(\lambda) d \lambda+h_{b 1} \int_{0}^{1}(1-\lambda)^{2} g(\lambda) d \lambda$

$$
=h_{b 1}+2\left(h_{b 2}-h_{b 1}\right) M+\left(h_{b 1}-2 h_{b 2}\right)\left(M^{2}+V\right)(>0, \text { by the definition of } \mathrm{Y}),
$$

$V=E\left(\lambda^{2}\right)-M^{2}$, is the variance of random variable $\lambda$, and $G\left(\pi_{x}\right)=\frac{\beta_{0} \pi_{x}^{2}}{\pi_{0}}+\pi_{0}-\beta_{0} \pi_{x}$

\subsection{Vendor's expected total cost per unit time}

When the vendor produces the first $q$ units, the vendor will deliver them to the buyer. After that the vendor will schedule the deliveries on the average every $(1-\lambda) q / D$ units of time until the inventory level falls to zero. Hence, the total inventory per unit time for the vendor is

$$
\left[m q\left(\frac{q}{P}+(m-1) \frac{(1-\lambda) q}{D}\right)-\frac{m^{2} q^{2}}{2 P}\right]-\left[\frac{(1-\lambda) q^{2}}{D}(1+2+\ldots \ldots . .+(m-1))\right]=\frac{m q^{2}}{P}-\frac{m^{2} q^{2}}{2 P}+\frac{m(m-1)(1-\lambda) q^{2}}{2 D}
$$

The vendor's cost per production cycle is the sum of the set-up cost, defective items treatment cost and inventory holding cost, and can be expressed as:

$$
T C_{v}\left(q, \pi_{x}, m\right)=A_{v}+h_{v 2} m \lambda q+m q^{2} h_{v 1}\left[\frac{1}{P}-\frac{m}{2 P}+\frac{(m-1)(1-\lambda)}{2 D}\right]
$$

The expected number of production cycles per unit time is $D /(1-M) m q$, hence the total expected cost per unit time is given by

$$
\operatorname{ETC}_{v}\left(q, \pi_{x}, m\right)=E\left[T C_{v}\left(q, \pi_{x}, m\right)\right] \frac{D}{(1-M) m q}=\frac{D A_{v}}{(1-M) m q}+\frac{D M h_{v 2}}{(1-M)}+\frac{D q h_{v 1}}{(1-M)}\left[\frac{1}{P}-\frac{m}{2 P}+\frac{(m-1)}{2 D}(1-M)\right]
$$

\subsection{Integrated supply chain inventory model}

Under integrated model, the buyer and the vendor cooperate with each other. We analyze the system in which a central planner makes all decisions to minimize the total expected cost of the entire supply chain. In this case, the vendor and buyer negotiate to decide the optimal shipping quantity q, reorder point $r$, lead time L, backorder price discount $\pi_{x}$ and optimal number of lots $\mathrm{m}$ together. The integrated cost of supply chain is given by

$$
\begin{aligned}
& \operatorname{ETC}_{S c}\left(q, r, \pi_{x}, L, m\right)=\operatorname{ETC}_{b}\left(q, r, \pi_{x}, L, m\right)+E T C_{v}\left(q, \pi_{x}, m\right) \\
& =\frac{D}{(1-M) q}\left[A_{b}+\frac{A_{v}}{m}+F+C(L)+G\left(\pi_{x}\right) E(X-r)^{+}\right]+\frac{D\left(s+M h_{v 2}\right)}{(1-M)}+\frac{Y q}{2(1-M)}+h_{b 1}[r-D L+ \\
& \left.\left(1-\frac{\beta_{0} \pi_{x}}{\pi_{0}}\right) E(X-r)^{+}\right]+\frac{D q h_{v 1}}{(1-M)}\left[\frac{1}{P}-\frac{m}{2 P}+\frac{(m-1)(1-M)}{2 D}\right]
\end{aligned}
$$

We can see that the vendor-buyer supply chain inventory model given in Eq. (3) overlooked the possible relationship between quality and lot size, which is unrealistic. We shall then modify Eq. (3) by considering the following assumption made in the model proposed by Porteus (1986). In the production 
process, the process can go out of control with a given probability $\theta$. Therefore, the expected number of defective items in a lot of size $m(1-M) q$ is approximated by $m^{2}(1-M)^{2} q^{2} \frac{\theta}{2}$ for more details, see Porteus (1986). Suppose $d$ is the cost of replacing a defective unit. Thus, the expected cost per year of replacing a defective item is given by $\operatorname{Ddm}(1-M) q \frac{\theta}{2}$. Therefore, the total expected annual cost incorporating defective items replacement cost can be expressed as

$$
\operatorname{DETC}_{S c}\left(q, r, \pi_{x}, L, m\right)=E T C_{S c}\left(q, r, \pi_{x}, L, m\right)+\frac{1}{2} D d m(1-M) q \theta
$$

\subsection{Investment in quality improvement}

Based on Eq. (4), we will study the effect of investment on quality improvement. As in Porteus (1986), a logarithmic investment function is assumed for investment in quality improvement. Consider $I(\theta)=$ $\alpha b \ln \left(\frac{\theta_{0}}{\theta}\right)$ as the opportunity cost of quality improvement investment, where $\theta_{0}$ is the original probability of the out of control production process, and $b=\frac{1}{\delta}$ with $\delta$ being the percentage decrease in $\theta$ per dollar increase in $I(\theta)$. Thus, the joint total expected cost given by eq. (4), transforms to

$$
\begin{aligned}
& \operatorname{DETC}_{S c}\left(q, r, \pi_{x}, L, m, \theta\right)=\frac{D}{(1-M) q}\left[A_{b}+\frac{A_{v}}{m}+F+C(L)+G\left(\pi_{x}\right) E(X-r)^{+}\right]+\frac{D\left(s+M h_{v 2}\right)}{(1-M)} \\
& +\frac{Y q}{2(1-M)}+h_{b 1}\left[r-D L+\left(1-\frac{\beta_{0} \pi_{x}}{\pi_{0}}\right) E(X-r)^{+}\right]+\frac{D q h_{v 1}}{(1-M)}\left[\frac{1}{P}-\frac{m}{2 P}+\frac{(m-1)(1-M)}{2 D}\right] \\
& +\frac{1}{2} D d m(1-M) q \theta+\alpha b \ln \left(\frac{\theta_{0}}{\theta}\right)
\end{aligned}
$$

\subsection{Lead time demand follows a normal distribution}

We assume that the lead time demand $X$ is normally distributed with finite mean $D L$, standard deviation $\sigma \sqrt{L}$, and reorder point $r=D L+k \sigma \sqrt{L}$. Therefore the expected shortages quantity at the end of the cycle is given by

$$
E(X-r)^{+}=\int_{R}^{\infty}(x-r) d f_{X}(x)=\sigma \sqrt{L} \psi(k)>0, \text { where } \psi(k)=\phi(k)-k[1-\Phi(k)]>0,
$$

where $\varnothing$ and $\Phi$ denote the standard normal probability density function and distribution function respectively. Therefore, considering the safety factor $k$ as a decision variable instead of $r$, the objective is to minimize the following cost function

$$
\begin{aligned}
& \operatorname{DETC}_{S c}\left(q, k, \pi_{x}, L, m, \theta\right)=\frac{D}{(1-M) q}\left[A_{b}+\frac{A_{v}}{m}+F+C(L)+G\left(\pi_{x}\right) \sigma \sqrt{L} \psi(k)\right]+\frac{D\left(s+M h_{v 2}\right)}{(1-M)} \\
& +\frac{Y q}{2(1-M)}+h_{b 1}\left[k+\left(1-\frac{\beta_{0} \pi_{x}}{\pi_{0}}\right) \psi(k)\right] \sigma \sqrt{L}+\frac{D q h_{v 1}}{(1-M)}\left[\frac{1}{P}-\frac{m}{2 P}+\frac{(m-1)(1-M)}{2 D}\right] \\
& +\frac{1}{2} D d m(1-M) q \theta+\alpha b \ln \left(\frac{\theta_{0}}{\theta}\right) .
\end{aligned}
$$

In order to find the optimal values of decision variables, we relax the integer constraint on $m$, let us take the partial derivatives of $D E T C_{S C}\left(q, r, \pi_{x}, L, m, \theta\right)$ with respect to $q, k, \theta, \pi_{x}$ and $L \in\left[L_{i}, L_{i-1}\right]$, we obtain $\frac{\partial \operatorname{DETC}_{S C}\left(q, k, \pi_{x}, L, m, \theta\right)}{\partial q}=-\frac{D}{(1-M) q^{2}}\left[A_{b}+\frac{A_{v}}{m}+F+C(L)+G\left(\pi_{x}\right) \sigma \sqrt{L} \psi(k)\right]+\frac{1}{2(1-M)}$ 
$\left[Y+h_{v 1}\left[\frac{(2-m) D}{P}+(m-1)(1-M)\right]\right]+\frac{1}{2} D d m(1-M) \theta$

$\frac{\partial D E T C_{S C}\left(q, k, \pi_{x}, L, m, \theta\right)}{\partial k}=\sigma \sqrt{L}\left\{h_{b 1}+\left[\frac{D G\left(\pi_{x}\right)}{(1-M) q}+h_{b 1}\left(1-\frac{\beta_{0} \pi_{x}}{\pi_{0}}\right)\right][\Phi(k)-1]\right\}$

$\frac{\partial D E T C_{S C}\left(q, k, \pi_{x}, L, m, \theta\right)}{\partial \theta}=\frac{1}{2} \operatorname{Ddm}(1-M) q-\frac{\alpha b}{\theta}$

$\frac{\partial D E T C_{S C}\left(q, k, \pi_{x}, L, m, \theta\right)}{\partial \pi_{x}}=\frac{\beta_{0} \sigma \sqrt{L} \psi(k)}{\pi_{0}}\left[\frac{D\left(2 \pi_{x}-\pi_{0}\right)}{(1-M) q}-h_{b 1}\right]$

$\frac{\partial \operatorname{DETC}_{S C}\left(q, k, \pi_{x}, L, m, \theta\right)}{\partial L}=\frac{D}{(1-M) q}\left[\frac{G\left(\pi_{x}\right) \sigma \psi(k)}{2 \sqrt{L}}-C_{i}\right]+\frac{h_{b 1} \sigma}{2 \sqrt{L}}\left[k+\left(1-\frac{\beta_{0} \pi_{x}}{\pi_{0}}\right) \psi(k)\right]$

By examining the second-order sufficient condition for a minimum value, it can be verified that $\operatorname{DETC}_{S C}\left(q, k, \pi_{x}, L, m, \theta\right)$ is not a convex function of $\left(q, k, \pi_{x}, m, \theta\right)$. However, for fixed $\left(q, k, \pi_{x}, m, \theta\right)$, $\operatorname{DETC}_{S C}\left(q, k, \pi_{x}, L, m, \theta\right)$ is concave in $L \in\left[L_{i}, L_{i-1}\right]$, because $\frac{\partial^{2} D E T C_{S C}\left(q, k, \pi_{x}, L, m, \theta\right)}{\partial L^{2}}=-\frac{\sigma}{2} L^{-3 / 2}\left\{\frac{D G\left(\pi_{x}\right) \psi(k)}{(1-M) q}+h_{b 1}\left[k+\left(1-\frac{\beta_{0} \pi_{x}}{\pi_{0}}\right) \psi(k)\right]\right\}<0$

Hence, for fixed $\left(q, k, \pi_{x}, m\right)$, the minimum joint total expected cost per unit time will occur at the end points of the interval $\left[L_{i}, L_{i-1}\right], i=1,2, n$. On the other hand, by setting Eqs. (7-10) equal to zero, we obtain

$$
\begin{aligned}
& \frac{\partial \operatorname{DETC}_{S C}\left(q, k, \pi_{x}, L, m, \theta\right)}{\partial q}=0 \\
& \Rightarrow q=\sqrt{\frac{2 D P\left[A_{b}+\frac{A_{v}}{m}+F+C(L)+G\left(\pi_{x}\right) \sigma \sqrt{L} \psi(k)\right]}{P Y+D P d m(1-M)^{2} \theta+h_{v 1}[D(2-m)+P(m-1)(1-M)]}} \\
& \frac{\partial D E T C_{S C}\left(q, k, \pi_{x}, L, m, \theta\right)}{\partial k}=0 \Rightarrow 1-\Phi(k)=h_{b 1} /\left[\frac{D G\left(\pi_{x}\right)}{(1-M) q}+h_{b 1}\left(1-\frac{\beta_{0} \pi_{x}}{\pi_{0}}\right)\right] \\
& \frac{\partial D E T C_{S C}\left(q, k, \pi_{x}, L, m, \theta\right)}{\partial \theta}=0 \Rightarrow \theta=\frac{2 \alpha b}{D d m(1-M) q} \\
& \frac{\partial D E T C_{S C}\left(q, k, \pi_{x}, L, m, \theta\right)}{\partial \pi_{x}}=0 \Rightarrow \pi_{x}=\frac{1}{2}\left[\pi_{0}+\frac{q h_{b 1}}{D}(1-M)\right]
\end{aligned}
$$

For fixed $m$ and $L \in\left[L_{i}, L_{i-1}\right]$, by solving Eqs. (12-15) we can obtain the values of $q, k, \theta$ and $\pi_{x}$ (we denote these values by $q^{*}, k^{*}, \theta^{*}$ and $\pi_{x}^{*}$ respectively). The following proposition asserts that, for fixed 
$\mathrm{m}$ and $L \in\left[L_{i}, L_{i-1}\right]$, when the integer constraint in $\mathrm{m}$ is ignored, the point $\left(q^{*}, k^{*}, \theta^{*}, \pi_{x}^{*}\right)$ is the optimal solution such that the joint total expected cost per unit time has a minimum value.

Proposition: For fixed $m$ and $L \in\left[L_{i}, L_{i-1}\right]$, the hessian matrix for $\operatorname{DETC}_{S C}\left(q, k, \pi_{x}, L, m, \theta\right)$ is positive definite at $\operatorname{point}\left(q^{*}, k^{*}, \theta^{*}, \pi_{x}^{*}\right)$.

Proof See appendix.

Next, in order to examine the effect of $m$ on the joint total expected cost per unit time, we take the first and second partial derivatives of $\operatorname{DETC}_{S C}\left(q, k, \pi_{x}, L, m, \theta\right)$ with respect to $\mathrm{m}$, we obtain

$$
\begin{aligned}
& \frac{\partial D E T C_{S C}\left(q, k, \pi_{x}, L, m, \theta\right)}{\partial m}=-\frac{D A_{v}}{(1-M) m^{2} q}+\frac{D q h_{v 1}}{(1-M)}\left[-\frac{1}{2 P}+\frac{(1-M)}{2 D}\right]+\frac{1}{2} D d(1-M) q \theta \\
& \frac{\partial^{2} D E T C_{S C}\left(q, k, \pi_{x}, L, m, \theta\right)}{\partial m^{2}}=\frac{2 D A_{v}}{(1-M) m^{3} q}>0
\end{aligned}
$$

Therefore $D E T C_{S C}\left(q, k, \pi_{x}, L, m, \theta\right)$ is convex respect to $m$, for fixed $\left(q, k, \pi_{x}, \theta\right)$ and $L \in\left[L_{i}, L_{i-1}\right]$, as a result, the search for the optimal shipment number, $m^{*}$ is reduced to find a local minimum. The optimal solution of $q, k, \theta$ and $\pi_{x}$ for given $\mathrm{L}$ and $\mathrm{m}$ can be obtained by solving Eqs. (12-15) iteratively until convergence. Therefore, we can establish the following algorithm to find the optimal values $\left(q^{*}, k^{*}, \theta^{*}, \pi_{x}^{*}, L^{*}, m^{*}\right)$. We note that $\theta^{*}$ is positive as the parameters $\alpha, \mathrm{b}$ and $\delta$ are positive. Also, if $\theta^{*}<\theta_{0}$ then $\left(q^{*}, k^{*}, \theta^{*}, \pi_{x}^{*}, m^{*}\right)$ is the optimal solution for a given $L \in\left[L_{i}, L_{i-1}\right]$. However if $\theta^{*} \geq \theta_{0}$ then it is unrealistic to invest in improving process quality; in this case, $\theta^{*}=\theta_{0}$.

\section{Algorithm}

Step 1: Set $\mathrm{m}=1$.

Step 2: For each $L_{i}, i=0,1,2, n$, perform (i) to (v)

(i) Start with $\mathrm{k}_{1}=0$ (implies $\psi\left(\mathrm{k}_{1}\right)=0.3989$, which can be obtained by checking the standard normal table, as $\phi\left(\mathrm{k}_{1}\right)=0.3989$ and $\left.\Phi\left(\mathrm{k}_{1}\right)=0.5\right)$. Also set $\theta_{1}=\theta_{0}$ and. $\pi_{x 1}=\pi_{0}$.

(ii) Substituting the values of $\psi\left(k_{1}\right), \theta_{1}$ and $\pi_{x_{1}}$ into eqn. (12) to evaluate $q_{1}$.

(iii) Utilizing $q_{1}$ and $\pi_{x 1}$ to determine $\Phi\left(\mathrm{k}_{2}\right)$ from eqn. (13), then finds $\mathrm{k}_{2}$ by checking the standard normal table, and hence $\psi\left(k_{2}\right)$.

(iv) Also use $q_{1}$ to determine $\theta_{2}$ from eqn. (14) and $\pi_{x 2}$ from eqn. (15).

(v) Repeat (ii) - (iv) until no change occurs in the values of $\left(q_{i}, k_{i}, \theta_{i}, \pi_{x i}\right)$.

Step 3: Compare $\pi_{x i}$ with $\pi_{0}$, and $\theta_{i}$ with $\theta_{0}$, there are following possibilities

(a) If $\pi_{x_{i}}<\pi_{0}$ and $\theta_{i}<\theta_{0}$ then the solution obtain in step 2 is optimal for given $L_{i}$. Denote this solution by $\left(q_{i}^{*}, k_{i}^{*}, \theta_{i}^{*}, \pi_{x i}^{*}\right)$, go to step 4 .

(b) If $\pi_{x_{i}} \geq \pi_{0}$ and $\theta_{i}<\theta_{0}$ then $\pi_{x i}^{*}$ is not feasible. Set $\pi_{x i}^{*}=\pi_{0}$ and calculate the corresponding values of $\left(q_{i}, k_{i}, \theta_{i}, \pi_{x_{i}}\right)$ from eqns. (12)-(15) iteratively until convergence (the solution procedure is similar to that given in step 2). If now $\pi_{x_{i}}<\pi_{0}$ then the optimal solution is obtained, consider it $\left(q_{i}^{*}, k_{i}^{*}, \theta_{i}^{*}, \pi_{x i}^{*}\right)$, go to step 4; otherwise, go to step 3 . 
(c) If $\theta_{i} \geq \theta_{0}$ and $\pi_{x_{i}}<\pi_{0}$ then $\theta_{i}$ is not optimal. Set $\theta_{i}=\theta_{0}$ and evaluate the corresponding values of $\left(q_{i}, k_{i}, \theta_{i}, \pi_{x_{i}}\right)$ from eqns. (12)-(15) iteratively until convergence. If now $\theta_{i}<\theta_{0}$ then $\left(q_{i}^{*}, k_{i}^{*}, \theta_{i}^{*}, \pi_{x i}^{*}\right)$, is the optimal solution and go to step 4 ; otherwise, go to step 3 .

(d) If $\pi_{x_{i}} \geq \pi_{0}$ and $\theta_{i} \geq \theta_{0}$ then go to step 3 .

Step 4: For $\left(q_{i}^{*}, k_{i}^{*}, \theta_{i}^{*}, \pi_{x i}^{*}\right)$, compute $\operatorname{DETC}_{S c}\left(q_{i}^{*}, k_{i}^{*}, \theta_{i}^{*}, \pi_{x i}^{*}, L_{i}, m\right)$

Step 5: Find $\operatorname{Min} \operatorname{DETC}_{S C}\left(q_{i}^{*}, k_{i}^{*}, \theta_{i}^{*}, \pi_{x i}^{*}, L_{i}, m\right)$ Let $i=0,1,2, \ldots, n$

$\min _{i=0,1,2, \ldots, n} \operatorname{DETC}_{S C}\left(q_{i}^{*}, k_{i}^{*}, \theta_{i}^{*}, \pi_{x i}^{*}, L_{i}, m\right)=\operatorname{DETC} C_{S c}\left(q_{(m)}^{*}, k_{(m)}^{*}, \theta_{(m)}^{*}, \pi_{x(m)}^{*}, L_{(m)}^{*}, m\right)$ then $\left(q_{(m)}^{*}, k_{(m)}^{*}, \theta_{(m)}^{*}, \pi_{x_{(m)}}^{*}, L_{(m)}^{*}\right)$ is the optimal solution for the fixed $\mathrm{m}$.

Step 6: Set $\mathrm{m}=\mathrm{m}+1$, repeat steps 2- steps 5 to get $\operatorname{DETC}_{S c}\left(q_{(m)}^{*}, k_{(m)}^{*}, \theta_{(m)}^{*}, \pi_{x_{(m)}}^{*}, L_{(m)}^{*}, m\right)$

Step 7: If following then go to step 6, otherwise go to step 8 . $\operatorname{DETC}_{S C}\left(q_{(m)}^{*}, k_{(m)}^{*}, \theta_{(m)}^{*}, \pi_{x_{(m)}}^{*}, L_{(m)}^{*}, m\right) \leq \operatorname{DETC}_{S C}\left(q_{(m-1)}^{*}, k_{(m-1)}^{*}, \theta_{(m-1)}^{*}, \pi_{x_{(m-1)}}^{*}, L_{(m-1)}^{*}, m-1\right)$ Step 8: Set $\left(q^{*}, k^{*}, \theta^{*}, \pi_{x}^{*}, L^{*}, m\right)=\left(q_{(m-1)}^{*}, k_{(m-1)}^{*}, \theta_{(m-1)}^{*}, \pi_{x_{(m-1)}^{*}}^{*}, L_{(m-1)}^{*}, m-1\right)$, which is the optimal solution, on which we get minimum joint expected cost per unit time.

Step 9: Once we obtain the optimal solution $\left(q^{*}, k^{*}, \theta^{*}, \pi_{x}^{*}, L^{*}, m\right)$ the optimal reorder point $r^{*}=D L^{*}+k^{*} \sigma \sqrt{L^{*}}$ the optimal backorder ratio $\beta^{*}=\frac{\beta_{0} \pi_{x}^{*}}{\pi_{0}}$ and the optimal ordering quantity $Q^{*}=m q^{*}(1-M)$ are followed.

\section{Numerical example}

In order to illustrate the above solution procedure and the effects of taking backorder price discount as a decision variable along with reorder point, let us consider an inventory system with the data used in Wu and Ouyang (2001): $\mathrm{D}=600$ units/year, $\mathrm{A}_{\mathrm{b}}=\$ 200 /$ order, $\pi_{o}=\$ 150 /$ unit, $\sigma=7$ units/week, where we consider 1 year $=52$ weeks and the lead time has three components with data shown in Table 1 .

Table 1

Lead time data

\begin{tabular}{cccc}
\hline $\begin{array}{c}\text { Lead time } \\
\text { Component, } \mathrm{i}\end{array}$ & $\begin{array}{c}\text { Normal duration } \\
\mathrm{b}_{\mathrm{i}} \text { (days) }\end{array}$ & $\begin{array}{c}\text { Minimum duration } \\
\mathrm{a}_{\mathrm{i}} \text { (days) }\end{array}$ & $\begin{array}{c}\text { Unit crashing cost } \\
\mathrm{c}_{\mathrm{i}}(\$ / \text { day })\end{array}$ \\
\hline 1 & 20 & 6 & 0.4 \\
2 & 20 & 6 & 1.2 \\
3 & 20 & 9 & 5.0 \\
\hline
\end{tabular}

The defective rate $\lambda$ has a beta distribution of first kind with parameters $u=1$ and $v=4$; that is, the p.d.f. of $\lambda$ is given by

$$
g(\lambda)= \begin{cases}4(1-\lambda)^{3}, & 0<\lambda<1 \\ 0, & \text { otherwise }\end{cases}
$$


Mean of $\lambda$ is $M=\frac{u}{u+v}=\frac{1}{5}$ and the variance of $\lambda$ is $V=\frac{u v}{(u+v)^{2}(u+v+1)}=\frac{2}{75}$

Besides these, we take $\mathrm{P}=2000$ units/year, $\mathrm{A}_{\mathrm{v}}=\$ 1500 /$ Set-up, $\mathrm{s}=\$ 1.6 /$ unit, $\mathrm{F}=\$ 30 /$ shipment, $\mathrm{h}_{\mathrm{vl}}=$ $\$ 20 /$ unit, $_{\mathrm{v} 2}=\$ 30 / \mathrm{unit} \mathrm{h}_{\mathrm{b} 1}=\$ 25 / \mathrm{unit}_{\mathrm{b} 2}=\$ 15 /$ unit, $\mathrm{d}=\$ 40 /$ unit, $\alpha=0.1 /$ /year, $\delta=0.0025, \theta_{0}=0.0002$. Applying the proposed algorithm, we solve the problem when the upper bound of the backorder ratio $\beta_{o}=0,0.5,0.8$ and 1; and tabulated the results in Table 2. Further, the computed results are summarized in Table 3 for optimal inventory policy by comparing $\operatorname{DETC}_{S c}\left(q_{i}^{*}, k_{i}^{*}, \theta_{i}^{*}, \pi_{x i}^{*}, L_{i}, m\right)$ for $i=0,1,2,3$ and to prove the effects of backorder price discount, we list the saving in the same table based on the no-price discount policy. From the Table 3 , it is seen that as the value of upper bound of the backorder ratio $\beta_{o}$ increases, joint expected total annual cost, order quantity and backorder price discount decrease simultaneously. It also observe that $\operatorname{DETC}_{S C}\left(q, k, \pi_{x}, L, m, \theta\right)$ has minimum value when $\beta=1$ (complete backorder case) and maximum value when $\beta=0$ (complete lost sales case).

Table 2

Solution procedures of numerical example ( $\mathrm{L}_{\mathrm{i}}$ in weeks)

\begin{tabular}{|c|c|c|c|c|c|c|c|c|}
\hline$\beta_{o}$ & $\mathrm{~m}$ & $\mathrm{~L}$ & $\mathrm{C}(\mathrm{L})$ & $\mathrm{q}$ & $\mathrm{k}$ & $\theta$ & $\pi_{x}$ & $\operatorname{DETC}_{s c}()$. \\
\hline \multirow{4}{*}{0} & 1 & 4 & 22.4 & 283.8609 & 1.561 & 0.000014679 & 79.7310 & 15820 \\
\hline & 2 & 4 & 22.4 & 183.1708 & 1.762 & 0.000011374 & 78.0528 & 14877 \\
\hline & 3 & 4 & 22.4 & 140.6449 & 1.877 & 0.000009875 & 77.3441 & 14766 \\
\hline & 4 & 4 & 22.4 & 116.5015 & 1.957 & 0.000008941 & 76.9417 & 14845 \\
\hline \multirow{4}{*}{0.5} & 1 & 4 & 22.4 & 284.0049 & 1.488 & 0.000014671 & 79.7334 & 15880 \\
\hline & 2 & 4 & 22.4 & 183.3156 & 1.695 & 0.000011365 & 78.0553 & 14895 \\
\hline & 3 & 4 & 22.4 & 140.7025 & 1.815 & 0.000009871 & 77.3450 & 14747 \\
\hline & 4 & 4 & 22.4 & 116.5609 & 1.896 & 0.000008937 & 76.9427 & 14827 \\
\hline \multirow{4}{*}{0.8} & 1 & 4 & 22.4 & 284.1239 & 1.437 & 0.000014665 & 79.7354 & 15865 \\
\hline & 2 & 4 & 22.4 & 183.3699 & 1.650 & 0.000011361 & 78.0562 & 14881 \\
\hline & 3 & 4 & 22.4 & 140.7676 & 1.772 & 0.000009866 & 77.3461 & 14735 \\
\hline & 4 & 4 & 22.4 & 116.6155 & 1.855 & 0.000008932 & 76.9436 & 14816 \\
\hline \multirow{4}{*}{1} & 1 & 4 & 22.4 & 284.2164 & 1.400 & 0.000014660 & 79.7369 & 15853 \\
\hline & 2 & 4 & 22.4 & 183.4282 & 1.617 & 0.000011358 & 78.0571 & 14871 \\
\hline & 3 & 4 & 22.4 & 140.8083 & 1.740 & 0.000009864 & 77.3468 & 14727 \\
\hline & 4 & 4 & 22.4 & 116.6262 & 1.825 & 0.000008932 & 76.9438 & 14807 \\
\hline
\end{tabular}

Table 3

Summary of the optimal solution of numerical example ( $\mathrm{L}^{*}$ in weeks)

\begin{tabular}{ccccccccccc}
\hline$\beta_{o}$ & $\mathrm{~m}^{*}$ & $\mathrm{~L}^{*}$ & $\mathrm{q}^{*}$ & $\mathrm{k}^{*}$ & $\theta^{*}$ & $\pi_{\mathrm{x}}{ }^{*}$ & $\mathrm{Q}^{*}$ & $\mathrm{r}^{*}$ & $\operatorname{DETC}_{S C}()$. & $\begin{array}{c}\text { Saving } \\
(\%)\end{array}$ \\
\hline 0 & 3 & 4 & 140.6449 & 1.877 & 0.000009875 & 77.3441 & 337.5478 & 72.4318 & 14766 & - \\
0.5 & 3 & 4 & 140.7025 & 1.815 & 0.000009871 & 77.3450 & 337.6860 & 71.5638 & 14747 & $0.11 \%$ \\
0.8 & 3 & 4 & 140.7676 & 1.772 & 0.000009866 & 77.3461 & 337.8422 & 70.9618 & 14735 & $0.47 \%$ \\
1 & 3 & 4 & 140.8083 & 1.740 & 0.000009864 & 77.3468 & 337.9399 & 70.5138 & 14727 & $0.69 \%$ \\
\hline
\end{tabular}

\section{Sensitivity Analysis}

1. The joint expected total annual cost $\operatorname{DETC}_{S C}\left(q, k, \pi_{x}, L, m, \theta\right)$ has a maximum value when $\beta=0($ lost sales case) and has a minimum value when $\beta=1$ (backordering case). Hence, for $0<\beta<1$,

$\left[\operatorname{DETC}_{S c}\left(q, k, \pi_{x}, L, m, \theta\right)\right]_{\beta=1}<\left[D E T C_{S c}\left(q, k, \pi_{x}, L, m, \theta\right)\right]_{\beta}<\left[D E T C_{s c}\left(q, k, \pi_{x}, L, m, \theta\right)\right]_{\beta=0}$

2. If $\beta=1$, Eq. (6) reduces to the joint expected total annual cost of the backorder case and hence Eq. (12) becomes 
$q_{\beta=1}=\sqrt{\frac{2 D P\left[A_{b}+\frac{A_{v}}{m}+F+C(L)+\pi_{x} \sigma \sqrt{L} \psi(k)\right]}{P Y+D P d m(1-M)^{2} \theta+h_{v 1}[D(2-m)+P(m-1)(1-M)]}}$

If $\beta=0$, Eq. (6) reduces to the lost sales case and then Eq. (12) becomes

$$
q_{\beta=0}=\sqrt{\frac{2 D P\left[A_{b}+\frac{A_{v}}{m}+F+C(L)+\pi_{0} \sigma \sqrt{L} \psi(k)\right]}{P Y+D P d m(1-M)^{2} \theta+h_{v 1}[D(2-m)+P(m-1)(1-M)]}}
$$

Since $\pi_{x} \leq \pi_{0}$ from above values of $\mathrm{q}$ we notice that for fixed $\mathrm{L}, \theta$ and $\mathrm{k}, q_{\beta=1} \leq q_{\beta=0}$. That is, the order quantity $\mathrm{Q}$ per cycle in the backorder case is less than the lost sales case and coincide only when $\pi_{x}=\pi_{0}$.

3. For fixed $\beta$ and $L \in\left[L_{i}, L_{i-1}\right]$, taking the derivative of Eq. (12) with respect to k, we obtain

$$
\frac{d q}{d k}=\frac{-D P G\left(\pi_{x}\right) \sigma \sqrt{L}[1-\Phi(k)]}{q\left\{P Y+D P d m(1-M)^{2} \theta+h_{v 1}[D(2-m)+P(m-1)(1-M)]\right\}}<0
$$

This means that decreasing the safety factor $\mathrm{k}$ or equivalently decreasing the reorder point $\mathrm{r}$, increases the shipping quantity $\mathrm{q}$ and consequently increases the order quantity $\mathrm{Q}$.

4. For fixed $\beta, \mathrm{k}$ and $L \in\left[L_{i}, L_{i-1}\right]$, taking the derivative of eqn.(12) with respect to $\mathrm{L}$, we obtain

$$
\frac{d q}{d L}=\frac{D P\left[\frac{1}{2} \pi_{1}-C_{i}\right]}{q\left\{P Y+D P d m(1-M)^{2} \theta+h_{v 1}[D(2-m)+P(m-1)(1-M)]\right\}}
$$

where $\pi_{1}=\frac{1}{L} G\left(\pi_{x}\right) \sigma \sqrt{L} \psi(k)$ is the stockout cost per unit time during lead time. Since D, P, q, Y, $h_{v 1}$ are all positive and $[D(2-m)+P(m-1)(1-M)]>0$ as $P(1-M)>D$. Therefore if $\pi_{1}>2 c_{i}$, we get $\frac{d q}{d L}>0$; this means increasing the lead time $\mathrm{L}$ increases the shipping quantity $q$ and consequently the order quantity $\mathrm{Q}$; and if $\pi_{1}<2 c_{i}$, we get $\frac{d q}{d L}<0$; this means increasing the lead time $\mathrm{L}$ decreases the shipping quantity q and consequently the order quantity $\mathrm{Q}$.

5. For fixed $\beta$, k and $L \in\left[L_{i}, L_{i-1}\right]$, taking the derivative of Eq. (12) with respect to $\mathrm{m}$, we obtain

$$
\begin{aligned}
& \frac{d q}{d m}=-\frac{1}{q\left\{P Y+D P d m(1-M)^{2} \theta+h_{v 1}[D(2-m)+P(m-1)(1-M)]\right\}^{2}}\left\{\frac { ( A _ { b } + A _ { v } ) } { m ^ { 2 } } \left[\frac{Y}{D}+h_{v 1}\right.\right. \\
& \left.\left[\frac{(m-1)(1-M)}{D}+\frac{(2-m)}{P}\right]+\frac{h_{v 1}}{P D}[P(1-M)-D]\left[A_{b}+\frac{A_{v}}{m}+F+C(L)+G\left(\pi_{x}\right) \sigma \sqrt{L} \psi(k)\right]\right\} \\
& <0(\because P(1-M)>D)
\end{aligned}
$$


This means that $\mathrm{q}$ and $\mathrm{m}$ are negatively related. It implies that as number of shipments $\mathrm{m}$ increases, shipping quantity q decreases, which is also supported by our numerical example.

\section{Conclusions}

In this paper, single-vendor, single-buyer integrated supply chain inventory model has been formulated, where the vendor produces a single product for the buyer with defective items. To improve the process quality for reducing number of defective items, an investment function has been used. Additionally, backorder price discount from the buyer to the customers has been taken into account to motivate them for backorders. The arrival lot may contain some defective items, so quality improvement was also incorporated in this paper. The purpose of this study was to minimize the total expected cost with order quantity, reorder point, backorder price discount, process quality, lead time and the number of shipments for each order as decision variables. An algorithm for finding the optimal solution has been developed, and a numerical example has been given to illustrate the results. Finally, sensitivity analysis of the key parameters has also been discussed. For future research, the model can be extended by considering fuzzy demand and delay-in-payments concepts in this model. Another extension of this model is to consider inflation and the time value of money.

\section{Acknowledgemet}

The authors would like to thank the anonymous referees for constructive comments on earlier version of this paper.

\section{References}

Annadurai, K., \& Uthayakumar, R. (2010). Controlling setup cost in (Q, r, L) inventory model with defective items. Applied Mathematical Modelling, 34(6), 1418-1427.

Ben-Daya, M., \& Raouf, A. (1994). Inventory models involving lead time as a decision variable. Journal of the Operational Research Society, 45(5), 579-582.

Chen, Y. C. (2013). An optimal production and inspection strategy with preventive maintenance error and rework. Journal of Manufacturing systems,32(1), 99-106.

Das, S. (2015). Impact of cash conversion cycle on cash holding-A study on FMCG sector. Accounting, 1(1), 1-16.

Gallego, G., \& Moon, I. (1993). The distribution free newsboy problem: review and extensions. Journal of the Operational Research Society, 44(8), 825-834.

Hong, J. D., \& Hayya, J. C. (1995). Joint investment in quality improvement and setup reduction. Computers \& Operations Research, 22(6), 567-574.

Hoque, M. A., \& Goyal, S. K. (2006). A heuristic solution procedure for an integrated inventory system under controllable lead-time with equal or unequal sized batch shipments between a vendor and a buyer. International Journal of Production Economics, 102(2), 217-225.

Hoque, M. A. (2007). An alternative model for integrated vendor-buyer inventory under controllable lead time and its heuristic solution. International journal of systems science, 38(6), 501-509.

Hwang, H., Kim, D.B., \& Kim, Y.D. (1993). Multiproduct economic lot size models with investments costs for setup reduction and quality improvement. International Journal of Production Research, 31(3), 691-703.

Jauhari, W.A., Pujawan, I.N., Wiratno, S.E., \& Priyandari, Y. (2011). Integrated inventory model for single vendor-single buyer with probabilistic demand. International Journal of Operational Research, $11(2), 160-178$.

Jindal, P., \& Solanki, A. (2014). Minimax distribution-free procedure for integrated inventory model with backorder price discount and controllable lead time. International Journal of Systems Science: Operations \& Logistics, 1(3), 131-141. 
Jindal, P., \& Solanki, A. (2016). Integrated vendor-buyer inventory models with inflation and time value of money in controllable lead time. Decision Science Letters, 5(1), 81-94.

Keller, G., \& Noori, H. (1988). Impact of investing in quality improvement on the lot size model. Omega, 16(6), 595-601.

Liao, C. J., \& Shyu, C. H. (1991). An analytical determination of lead time with normal demand. International Journal of Operations \& Production Management, 11(9), 72-78.

Lin, Y. J. (2008). Minimax distribution free procedure with backorder price discount. International Journal of Production Economics, 111(1), 118-128.

Lin, Y. J. (2009). An integrated vendor-buyer inventory model with backorder price discount and effective investment to reduce ordering cost. Computers \& Industrial Engineering, 56(4), 1597-1606.

Ma, W. M., \& Qiu, B. B. (2012). Distribution-free continuous review inventory model with controllable lead time and setup cost in the presence of a service level constraint. Mathematical Problems in Engineering, 2012.

Ouyang, L. Y., \& Chang, H. C. (2000). Impact of investing in quality improvement on (Q, r, L) model involving the imperfect production process.Production Planning \& Control, 11(6), 598-607.

Ouyang, L. Y., Wu, K. S., \& Ho, C. H. (2004). Integrated vendor-buyer cooperative models with stochastic demand in controllable lead time.International Journal of Production Economics, 92(3), 255-266.

Ouyang, L.Y., Wu, K.S., \& Ho, C.H. (2007). An integrated vendor-buyer inventory model with quality improvement and lead time reduction. International Journal of Production Economics, 108(12), 349358.

Ouyang, L. Y., Yeh, N. C., \& Wu, K. S. (1996). Mixture inventory model with backorders and lost sales for variable lead time. Journal of the Operational Research Society, 47(6), 829-832.

Pan, J. C. H., \& Hsiao, Y. C. (2005). Integrated inventory models with controllable lead time and backorder discount considerations. International Journal of Production Economics, 93, 387-397.

Pan, J. C. H., \& Yang, J. S. (2002). A study of an integrated inventory with controllable lead time. International Journal of Production Research, 40(5), 1263-1273.

Porteus, E. L. (1986). Optimal lot sizing, process quality improvement and setup cost reduction. Operations research, 34(1), 137-144.

Rosenblatt, M. J., \& Lee, H. L. (1986). Economic production cycles with imperfect production processes. IIE transactions, 18(1), 48-55.

Sarkar, B., \& Moon, I. (2014). Improved quality, setup cost reduction, and variable backorder costs in an imperfect production process. International Journal of Production Economics, 155, 204-213.

Sarkar, B., Mandal, B., \& Sarkar, S. (2015). Quality improvement and backorder price discount under controllable lead time in an inventory model.Journal of Manufacturing Systems, 35, 26-36.

Scarf, H., Arrow, K. J., \& Karlin, S. (1958). A min-max solution of an inventory problem. Studies in the mathematical theory of inventory and production, 10, 201-209.

Wu, K.S., \& Ouyang, L.Y. (2001). (Q, r, L) Inventory model with defective items. Computers and Industrial Engineering, 39, 173-185.

Wu, K. S., Ouyang, L. Y., \& Ho, C. H. (2007). Integrated vendor--buyer inventory system with sublot sampling inspection policy and controllable lead time. International Journal of Systems Science, 38(4), 339-350.

Yang, J. S., \& Pan, J. C. H. (2004). Just-in-time purchasing: an integrated inventory model involving deterministic variable lead time and quality improvement investment. International Journal of Production Research,42(5), 853-863. 


\section{Appendix A: Proof of Convexity}

To prove the convexity of $\operatorname{DETC}_{S c}\left(q, k, \pi_{x}, L, m, \theta\right)$ for fixed $\mathrm{m}$ and $\mathrm{L} \in\left[\mathrm{L}_{\mathrm{i}}, \mathrm{L}_{\mathrm{i}-1}\right]$. taking the Hessian matrix $\mathrm{H}$ as follows

$$
H=\left[\begin{array}{llll}
\frac{\partial^{2} D E T C_{S C}(.)}{\partial q^{2}} & \frac{\partial^{2} D E T C_{S C}(.)}{\partial q \partial k} & \frac{\partial^{2} D E T C_{S C}(.)}{\partial q \partial \pi_{x}} & \frac{\partial^{2} D E T C_{S C}(.)}{\partial q \partial \theta} \\
\frac{\partial^{2} D E T C_{S C}(.)}{\partial k \partial q} & \frac{\partial^{2} D E T C_{S C}(.)}{\partial k^{2}} & \frac{\partial^{2} D E T C_{S C}(.)}{\partial k \partial \pi_{x}} & \frac{\partial^{2} D E T C_{S C}(.)}{\partial k \partial \theta} \\
\frac{\partial^{2} D E T C_{S C}(.)}{\partial \pi_{x} \partial q} & \frac{\partial^{2} D E T C_{S C}(.)}{\partial \pi_{x} \partial k} & \frac{\partial^{2} D E T C_{S C}(.)}{\partial \pi_{x}^{2}} & \frac{\partial^{2} D E T C_{S C}(.)}{\partial \pi_{x} \partial \theta} \\
\frac{\partial^{2} D E T C_{S C}(.)}{\partial \theta \partial q} & \frac{\partial^{2} D E T C_{S C}(.)}{\partial \theta \partial k} & \frac{\partial^{2} D E T C_{S C}(.)}{\partial \theta \partial \pi_{x}} & \frac{\partial^{2} D E T C_{S C}(.)}{\partial \theta^{2}}
\end{array}\right]
$$

Where

$$
\begin{aligned}
& \frac{\partial^{2} D E T C_{S C}(.)}{\partial q^{2}}=\frac{2 D}{(1-M) q^{3}}\left[A_{b}+\frac{A_{v}}{m}+F+C(L)+G\left(\pi_{x}\right) \sigma \sqrt{L} \psi(k)\right] \\
& \frac{\partial^{2} D E T C_{S C}(.)}{\partial q \partial k}=\frac{\partial^{2} D E T C_{S C}(.)}{\partial k \partial q}=\frac{D \sigma \sqrt{L} G\left(\pi_{x}\right)}{(1-M) q^{2}}[1-\Phi(k)] \quad \frac{\partial^{2} D E T C_{S C}(.)}{\partial \pi_{x} \partial q}=\frac{\partial^{2} D E T C_{S C}(.)}{\partial q \partial \pi_{x}}=-\frac{D \sigma \sqrt{L} \beta_{0} \psi(k)}{(1-M) q^{2}}\left(\frac{2 \pi_{x}}{\pi_{0}}-1\right) \\
& \frac{\partial^{2} D E T C_{S C}(.)}{\partial q \partial \theta}=\frac{\partial^{2} D E T C_{S C}(.)}{\partial \theta \partial q}=\frac{1}{2} D d m(1-M) \frac{\partial^{2} D E T C_{S C}(.)}{\partial k^{2}}=\sigma \sqrt{L} \phi(k)\left[\frac{D G\left(\pi_{x}\right)}{(1-M) q}+h_{b 1}\left(1-\frac{\beta_{0} \pi_{x}}{\pi_{0}}\right)\right] \\
& \frac{\partial^{2} D E T C_{S C}(.)}{\partial k \partial \pi_{x}}=\frac{\partial^{2} D E T C_{S C}(.)}{\partial \pi_{x} \partial k}=-\beta_{0} \sigma \sqrt{L}\left[\frac{D}{(1-M) q}\left(\frac{2 \pi_{x}}{\pi_{0}}-1\right)-\frac{h_{b 1}}{\pi_{0}}\right][1-\Phi(k)]
\end{aligned}
$$




$$
\begin{array}{ll}
\frac{\partial^{2} D E T C_{S C}(.)}{\partial k \partial \theta}=\frac{\partial^{2} D E T C_{S C}(.)}{\partial \theta \partial k}=0 & \frac{\partial^{2} D E T C_{S C}(.)}{\partial \pi_{x} \partial \theta}=\frac{\partial^{2} D E T C_{S C}(.)}{\partial \theta \partial \pi_{x}}=0 \\
\frac{\partial^{2} D E T C_{S C}(.)}{\partial \pi_{x}^{2}}=\frac{2 D \beta_{0} \sigma \sqrt{L} \psi(k)}{\pi_{0}(1-M) q} & \frac{\partial^{2} D E T C_{S C}(.)}{\partial \theta^{2}}=\frac{\alpha b}{\theta^{2}}
\end{array}
$$

Now we evaluate the principal minors of $\mathrm{H}$ at point $\left(q^{*}, k^{*}, \theta^{*}, \pi_{x}^{*}\right)$. The first principal minor of $\mathrm{H}$ is $\left|H_{11}\right|=\frac{\partial^{2} D E T C_{S C}(.)}{\partial q^{2}}=\frac{2 D}{(1-M) q^{*}}\left[A_{b}+\frac{A_{v}}{m}+F+C(L)+G\left(\pi_{x}^{*}\right) \sigma \sqrt{L} \psi\left(k^{*}\right)\right]>0$

The second principal minor of $\mathrm{H}$ is

$$
\begin{aligned}
& \left|H_{22}\right|=\frac{2 D \sigma \sqrt{L} \phi\left(k^{*}\right)}{q^{*^{3}}(1-M)}\left[A_{b}+\frac{A_{v}}{m}+F+C(L)+G\left(\pi_{x}^{*}\right) \sigma \sqrt{L} \psi\left(k^{*}\right)\right]\left[\frac{D G\left(\pi_{x}^{*}\right)}{(1-M) q^{*}}+h_{b 1}\left(1-\frac{\beta_{0} \pi_{x}^{*}}{\pi_{0}}\right)\right] \\
& -\left[\frac{D \sigma \sqrt{L} G\left(\pi_{x}^{*}\right)}{(1-M) q^{*}}\left[1-\Phi\left(k^{*}\right)\right]\right]^{2}>\left[\frac{D \sigma \sqrt{L} G\left(\pi_{x}^{*}\right)}{(1-M) q^{*}}\right]^{2}\left[2 \phi\left(k^{*}\right) \psi\left(k^{*}\right)-\left[1-\Phi\left(k^{*}\right)\right]^{2}\right]>0
\end{aligned}
$$

Since as Ouyang et al. (2007) $\forall k^{*} \in[0, \infty), \psi\left(k^{*}\right), \phi\left(k^{*}\right)$ and $\eta\left(k^{*}\right)=2 \phi\left(k^{*}\right) \psi\left(k^{*}\right)-\left[1-\Phi\left(k^{*}\right)\right]^{2}$ are all positive (by examining the normal table).

The third principal minor of $\mathrm{H}$ is

$$
\begin{aligned}
& \left|H_{33}\right|=\frac{4 D^{2} \beta_{0}(\sigma \sqrt{L})^{2} \phi\left(k^{*}\right) \psi\left(k^{*}\right)}{\pi_{0}(1-M)^{2} q^{* 4}}\left[A_{b}+\frac{A_{v}}{m}+F+C(L)+G\left(\pi_{x}^{*}\right) \sigma \sqrt{L} \psi\left(k^{*}\right)\right]\left[\frac{D G\left(\pi_{x}^{*}\right)}{(1-M) q^{*}}+h_{b 1}\right. \\
& \left.\left(1-\frac{\beta_{0} \pi_{x}^{*}}{\pi_{0}}\right)\right]-\frac{2 D \beta_{0} \sigma \sqrt{L} \psi\left(k^{*}\right)}{\pi_{0}(1-M) q^{*}}\left[\frac{D \sigma \sqrt{L} G\left(\pi_{x}^{*}\right)}{(1-M) q^{*}}\left[1-\Phi\left(k^{*}\right)\right]\right]^{2}-\sigma \sqrt{L} \phi\left(k^{*}\right)\left[\frac{D G\left(\pi_{x}^{*}\right)}{(1-M) q^{*}}+h_{b 1}\right. \\
& \left.\left(1-\frac{\beta_{0} \pi_{x}^{*}}{\pi_{0}}\right)\right]\left[-\frac{D \sigma \sqrt{L} \beta_{0} \psi(k)}{(1-M) q^{2}}\left(\frac{2 \pi_{x}}{\pi_{0}}-1\right)\right]^{2} \\
& >\frac{4 D^{2} \beta_{0}(\sigma \sqrt{L})^{3} \phi\left(k^{*}\right)\left\{\psi\left(k^{*}\right)\right\}^{2} G\left(\pi_{x}^{*}\right)}{\pi_{0}(1-M)^{2} q^{* 4}}\left[\frac{D G\left(\pi_{x}^{*}\right)}{(1-M) q^{*}}+h_{b 1}\left(1-\frac{\beta_{0} \pi_{x}^{*}}{\pi_{0}}\right)\right]-\frac{\left.2 D^{3} \beta_{0}(\sigma \sqrt{L})^{3} \psi(k)^{*}\right)}{\pi_{0}(1-M)^{3} q^{* 5}}
\end{aligned}
$$




$$
\begin{aligned}
& \left\{G\left(\pi_{x}^{*}\right)\right\}^{2}\left[1-\Phi\left(k^{*}\right)\right]^{2}-\frac{D^{2} \beta_{0}^{2}(\sigma \sqrt{L})^{3} \phi\left(k^{*}\right)\left\{\psi\left(k^{*}\right)\right\}^{2}}{(1-M)^{2} q^{*}}\left(\frac{2 \pi_{x}^{*}}{\pi_{0}}-1\right)^{2}\left[\frac{D G\left(\pi_{x}^{*}\right)}{(1-M) q^{*}}+h_{b 1}\left(1-\frac{\beta_{0} \pi_{x}^{*}}{\pi_{0}}\right)\right] \\
& =\frac{D^{2} \beta_{0}(\sigma \sqrt{L})^{3} \phi\left(k^{*}\right)\left\{\psi\left(k^{*}\right)\right\}^{2}}{(1-M)^{2} q^{*} \pi_{0}}\left[\frac{D G\left(\pi_{x}^{*}\right)}{(1-M) q^{*}}+h_{b 1}\left(1-\frac{\beta_{0} \pi_{x}^{*}}{\pi_{0}}\right)\right]\left\{4 G\left(\pi_{x}^{*}\right)-\frac{\beta_{0}}{\pi_{0}}\left(2 \pi_{x}^{*}-\pi_{0}\right)^{2}\right\} \\
& -\frac{2 D^{3} \beta_{0}(\sigma \sqrt{L})^{3} \psi\left(k^{*}\right)\left\{G\left(\pi_{x}^{*}\right)\right\}^{2}}{\pi_{0}(1-M)^{3} q^{* 5}}\left[1-\Phi\left(k^{*}\right)\right]^{2}>\frac{2 D^{3} \beta_{0}(\sigma \sqrt{L})^{3} \psi\left(k^{*}\right) G\left(\pi_{x}^{*}\right)}{(1-M)^{3} q^{*^{5}}}\left\{2 \phi\left(k^{*}\right) \psi\left(k^{*}\right)-\frac{G\left(\pi_{x}^{*}\right)}{\pi_{0}}\left[1-\Phi\left(k^{*}\right)\right]^{2}\right\} \\
& =\frac{2 D^{3} \beta_{0}(\sigma \sqrt{L})^{3} \psi\left(k^{*}\right) G\left(\pi_{x}^{*}\right)}{(1-M)^{3} q^{* 5}}\left\{2 \phi\left(k^{*}\right) \psi\left(k^{*}\right)-\left[1+\frac{\beta_{0} \pi_{x}^{*}}{\pi_{0}^{2}}\left(\pi_{x}^{*}-\pi_{0}\right)\right]\left[1-\Phi\left(k^{*}\right)\right]^{2}\right\} \\
& =\frac{2 D^{3} \beta_{0}(\sigma \sqrt{L})^{3} \psi\left(k^{*}\right) G\left(\pi_{x}^{*}\right)}{(1-M)^{3} q^{*^{5}}}\left\{2 \phi\left(k^{*}\right) \psi\left(k^{*}\right)-\left[1-\Phi\left(k^{*}\right)\right]^{2}+\frac{\beta_{0} \pi_{x}^{*}}{\pi_{0}}\left(1-\frac{\pi_{x}^{*}}{\pi_{0}}\right)\right\}>0
\end{aligned}
$$

The fourth principal minor of $\mathrm{H}$ is

$$
\begin{aligned}
& \left|H_{44}\right|=\frac{\alpha b}{\theta^{2}} \frac{4 D^{2} \beta_{0}(\sigma \sqrt{L})^{2} \phi\left(k^{*}\right) \psi\left(k^{*}\right)}{\pi_{0}(1-M)^{2} q^{* 4}}\left[A_{b}+\frac{A_{v}}{m}+F+C(L)+G\left(\pi_{x}^{*}\right) \sigma \sqrt{L} \psi\left(k^{*}\right)\right]\left[\frac{D G\left(\pi_{x}^{*}\right)}{(1-M) q^{*}}+\right. \\
& \left.h_{b 1}\left(1-\frac{\beta_{0} \pi_{x}^{*}}{\pi_{0}}\right)\right]-\frac{\alpha b}{\theta^{2}} \frac{2 D \beta_{0} \sigma \sqrt{L} \psi\left(k^{*}\right)}{\pi_{0}(1-M) q^{*}}\left[\frac{D \sigma \sqrt{L} G\left(\pi_{x}^{*}\right)}{(1-M) q^{*}}\left[1-\Phi\left(k^{*}\right)\right]\right]^{2}-\frac{\alpha b}{\theta^{2}} \sigma \sqrt{L} \phi\left(k^{*}\right)\left[\frac{D G\left(\pi_{x}^{*}\right)}{(1-M) q^{*}}\right. \\
& \left.+h_{b 1}\left(1-\frac{\beta_{0} \pi_{x}^{*}}{\pi_{0}}\right)\right]\left[-\frac{D \sigma \sqrt{L} \beta_{0} \psi\left(k^{*}\right)}{(1-M) q^{* 2}}\left(\frac{2 \pi_{x}^{*}}{\pi_{0}}-1\right)\right]^{2}-\left(\frac{1}{2} D d m(1-M)\right)^{2} \frac{2 D \beta_{0}(\sigma \sqrt{L})^{2} \phi\left(k^{*}\right) \psi\left(k^{*}\right)}{\pi_{0}(1-M) q} \\
& {\left[\frac{D G\left(\pi_{x}^{*}\right)}{(1-M) q^{*}}+h_{b 1}\left(1-\frac{\beta_{0} \pi_{x}^{*}}{\pi_{0}}\right)\right]} \\
& >\frac{\alpha b}{\theta^{2}} \frac{4 D^{2} \beta_{0}(\sigma \sqrt{L})^{3} \phi\left(k^{*}\right)\left\{\psi\left(k^{*}\right)\right\}^{2} G\left(\pi_{x}^{*}\right)}{\pi_{0}(1-M)^{2} q^{*}}\left[\frac{D G\left(\pi_{x}^{*}\right)}{(1-M) q^{*}}+h_{b 1}\left(1-\frac{\beta_{0} \pi_{x}^{*}}{\pi_{0}}\right)\right]-\frac{\alpha b}{\theta^{2}} \frac{2 D^{3} \beta_{0}(\sigma \sqrt{L})^{3} \psi\left(k^{*}\right)}{\pi_{0}(1-M)^{3} q^{*}} \\
& \left\{G\left(\pi_{x}^{*}\right)\right\}^{2}\left[1-\Phi\left(k^{*}\right)\right]^{2}-\frac{\alpha b}{\theta^{2}} \frac{D^{2} \beta_{0}^{2}(\sigma \sqrt{L})^{3} \phi\left(k^{*}\right)\left\{\psi\left(k^{*}\right)\right\}^{2}}{(1-M)^{2} q^{* 4}}\left[\frac{D G\left(\pi_{x}^{*}\right)}{(1-M) q^{*}}+h_{b 1}\left(1-\frac{\beta_{0} \pi_{x}^{*}}{\pi_{0}}\right)\right]
\end{aligned}
$$




$$
\begin{aligned}
& \left(\frac{2 \pi_{x}^{*}}{\pi_{0}}-1\right)^{2}-\left(\frac{\alpha b}{\theta q}\right)^{2} \frac{2 D \beta_{0}(\sigma \sqrt{L})^{2} \phi\left(k^{*}\right) \psi\left(k^{*}\right)}{\pi_{0}(1-M) q}\left[\frac{D G\left(\pi_{x}^{*}\right)}{(1-M) q^{*}}+h_{b 1}\left(1-\frac{\beta_{0} \pi_{x}^{*}}{\pi_{0}}\right)\right] \\
& =\left(\frac{\alpha b}{\theta q}\right)^{2} \frac{D \beta_{0}(\sigma \sqrt{L})^{2} \phi\left(k^{*}\right) \psi\left(k^{*}\right)}{(1-M) q^{*} \pi_{0}}\left\{\frac{1}{\alpha b} \frac{D \sigma \sqrt{L} \psi\left(k^{*}\right)}{(1-M) q^{*}}\left[4 G\left(\pi_{x}^{*}\right)-\frac{\beta_{0}}{\pi_{0}}\left(2 \pi_{x}^{*}-\pi_{0}\right)^{2}\right]-2\right\} \\
& {\left[\frac{D G\left(\pi_{x}^{*}\right)}{(1-M) q^{*}}+h_{b 1}\left(1-\frac{\beta_{0} \pi_{x}^{*}}{\pi_{0}}\right)\right]-\frac{\alpha b}{\theta^{2}} \frac{2 D^{3} \beta_{0}(\sigma \sqrt{L})^{3} \psi\left(k^{*}\right)\left\{G\left(\pi_{x}^{*}\right)\right\}^{2}}{\pi_{0}(1-M)^{3} q^{* 5}}\left[1-\Phi\left(k^{*}\right)\right]^{2}} \\
& >\left(\frac{\alpha b}{\theta q}\right)^{2} \frac{D \beta_{0}(\sigma \sqrt{L})^{2} \phi\left(k^{*}\right) \psi\left(k^{*}\right)}{(1-M) q^{*} \pi_{0}} \frac{4 \pi_{0}}{\alpha b} \frac{D \sigma \sqrt{L} \psi\left(k^{*}\right)}{(1-M) q^{*}} \frac{D G\left(\pi_{x}^{*}\right)}{(1-M) q^{*}}-\frac{\alpha b}{\theta^{2}}\left[1-\Phi\left(k^{*}\right)\right]^{2} \\
& \frac{2 D^{3} \beta_{0}(\sigma \sqrt{L})^{3} \psi\left(k^{*}\right)\left\{G\left(\pi_{x}^{*}\right)\right\}^{2}}{\pi_{0}(1-M)^{3} q^{* 5}} \\
& =\frac{2 \alpha b D^{3} \beta_{0}(\sigma \sqrt{L})^{3} \psi\left(k^{*}\right) G\left(\pi_{x}^{*}\right)}{\theta^{2}(1-M)^{3} q^{* 5}}\left\{2 \phi\left(k^{*}\right) \psi\left(k^{*}\right)-\left[1-\Phi\left(k^{*}\right)\right]^{2}+\frac{\beta_{0} \pi_{x}^{*}}{\pi_{0}}\left(1-\frac{\pi_{x}^{*}}{\pi_{0}}\right)\right\}>0
\end{aligned}
$$

Since, all principal minors are positive, therefore hessian matrix $\mathrm{H}$ is positive definite. 